\title{
Intrapartum Vaginal Myomectomy of a Prolapsed Cervical Fibroid
}

\author{
${ }^{1}$ Vineeta Gupta, ${ }^{2}$ Nidhi Kumari, ${ }^{3}$ Madhuri Srivastava, ${ }^{4}$ Anuja Nanda
}

\begin{abstract}
Cervical and vaginal fibroid may be seen in less than $1 \%$ of the pregnant women. During labor, they may be responsible for obstruction or cervical dystocia. Usually in such cases, cesarean section is done to deliver the baby. An extensive literature search has shown only few case reports outlining vaginal myomectomy of a prolapsed cervical fibroid during pregnancy and none during labor. We are reporting a case of cervical fibroid which prolapsed outside the introitus during early labor resulting in obstructed labor for which intrapartum vaginal myomectomy was done to facilitate vaginal breech delivery.
\end{abstract}

Keywords: Cervical fibroid, Intrapartum vaginal myomectomy, Vaginal breech delivery, Obstructed labor.

How to cite this article: Gupta V, Kumari N, Srivastava M, Nanda A. Intrapartum Vaginal Myomectomy of a Prolapsed Cervical Fibroid. J South Asian Feder Menopause Soc 2014; 2(2):99-100.

\section{Source of support: Nil \\ Conflict of interest: None}

\section{INTRODUCTION}

Fibroid is seen in 20 to $30 \%$ of women in the reproductive age group. ${ }^{1}$ Cervical and vaginal fibroid may be seen in less than $1 \%$ of the pregnant women. ${ }^{2}$ During labor, they may be responsible for obstruction or cervical dystocia. Usually in such cases, cesarean section is done to deliver the baby. Myomectomy may be required during the antenatal period when there is associated pain not relieved with conservative measures, hemorrhage necessitating transfusion, or when degeneration of the fibroid leads to infection. An extensive literature search has shown only few case reports outlining vaginal myomectomy of a prolapsed cervical fibroid during pregnancy and we did not come across any case in which intrapartum vaginal myomectomy was done immediately

${ }^{1}$ Professor and Head, ${ }^{2}$ Senior Resident, ${ }^{3,4}$ Assistant Professor

${ }^{1-4}$ Department of Obstetrics and Gynecology, Shri Guru Ram Rai Institute of Medical and Health Sciences, Dehradun Uttarakhand, India

Corresponding Author: Vineeta Gupta, Professor and Head Department of Obstetrics and Gynecology, Shri Guru Ram Rai Institute of Medical and Health Sciences, Dehradun, Uttarakhand India, Phone: 919758284395, e-mail: vineetahims@yahoo.co.in followed by vaginal delivery. We are reporting a case of cervical fibroid which prolapsed outside the introitus during early labor resulting in obstructed labor for which intrapartum vaginal myomectomy was done to facilitate vaginal breech delivery.

\section{CASE REPORT}

A 35 years old unbooked woman G4P3L3 came to emergency with 34 weeks pregnancy and complain of some mass coming out per vaginum, pain lower abdomen and slight bleeding per vaginum for 12 hours. She had no known medical co-morbidity or surgical history. She was having severe pallor with tachycardia (130/min) and blood pressure was 130/90 mm Hg. On examination fundal height corresponded to 32 weeks of gestation, fetal heart sounds were absent and moderate contractions were present. A congested and inflamed mass of $12 \times 12 \mathrm{~cm}$ size was seen protruding out from the introitus resulting in obstructed labor (Fig. 1). On per vaginal examination, it appeared to originate from anterior lip of cervix and bag of membrane with fetal foot was felt posterior to the mass. Her investigations revealed hemoglobin of $6 \mathrm{gm} \%$ and increased TLC of $45300 / \mathrm{mm}^{3}$. Ultrasonography showed a fetus of 34 weeks gestation with breech presentation and absence of cardiac activity; and exact site of origin of the prolapsed fibroid was not clear. After preoperative preparation and cross-matching blood, patient was shifted to operation theater for excision of mass and vaginal delivery, if feasible. Patient was given lithotomy position and transverse incision was given over the cervical mass and the fibroid was enucleated completely from the anterior lip of cervix (Fig. 2). The bag of membranes ruptured spontaneously during the procedure and a dead male fetus was delivered by breech extraction followed by delivery of placenta. The redundant capsule wall was excised, hemostasis secured and anterior lip of cervix reconstructed (Fig. 3). Postoperative recovery of patient was uneventful. Histopathology showed features consistent with apoplectic leiomyoma and excised capsule showed features of ulceration with inflammation. By performing intrapartum vaginal myomectomy, we could conduct vaginal breech delivery thereby avoiding caesarean section. 


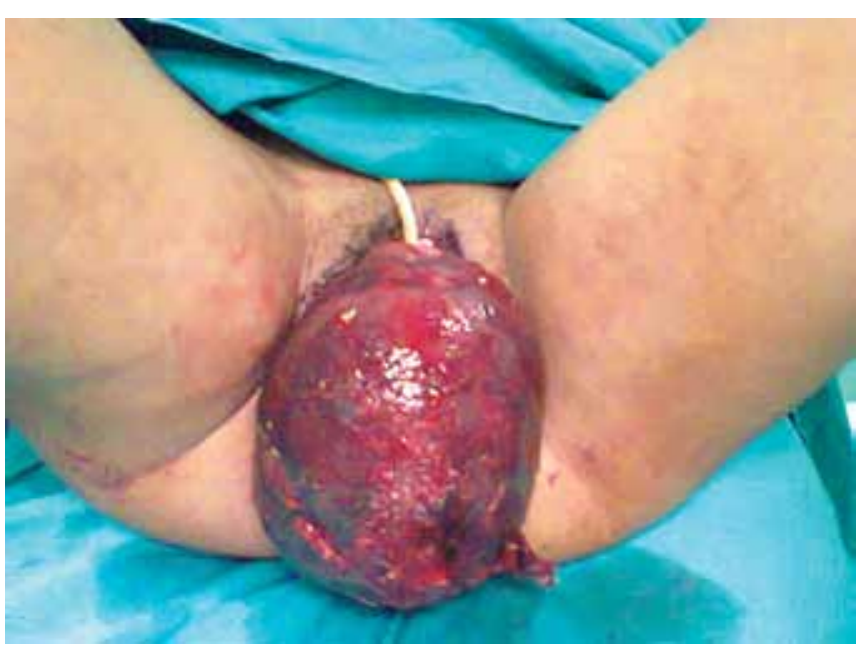

Fig. 1: Mass protruding outside the introitus

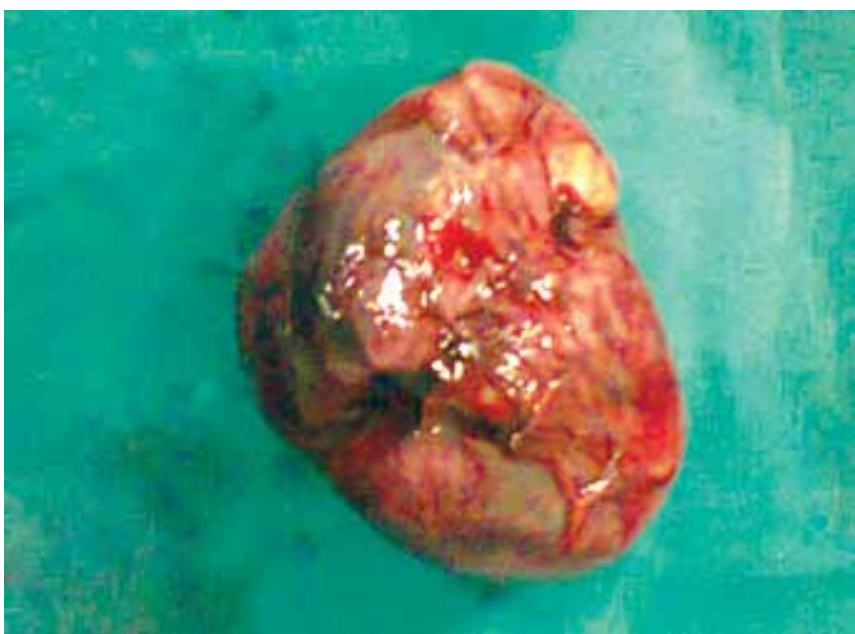

Fig. 2: Excised mass

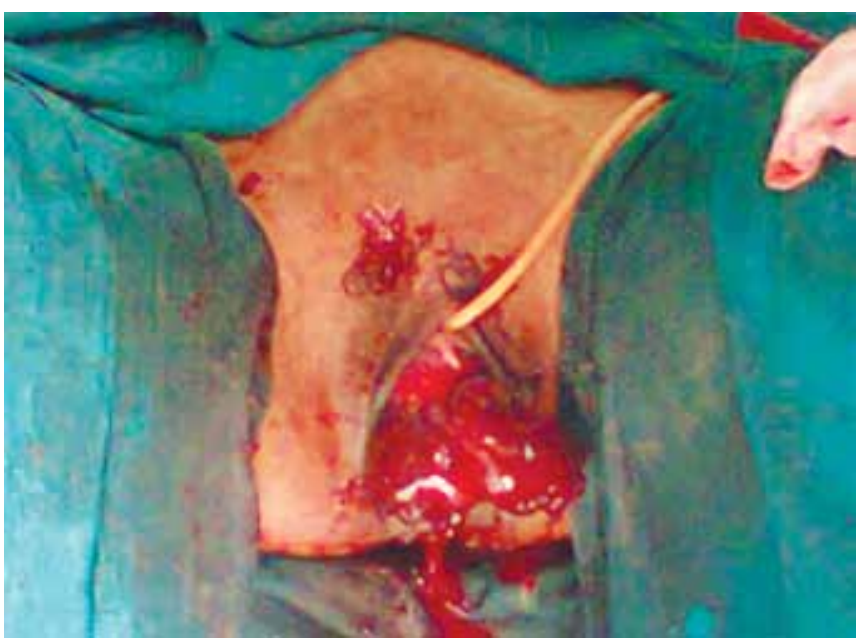

Fig. 3: Anterior lip of cervix after reconstruction

\section{DISCUSSION}

Prolapsed fibroids presenting during pregnancy are rare. Kilpatrick et al have described two cases of prolapsed cervical fibroids in which vaginal myomectomy has been performed during pregnancy. ${ }^{3}$ They reported that while vaginal myomectomy of a prolapsed cervical fibroid in pregnancy appears safe, it may be associated with rupture of membranes, necessitating termination of pregnancy. Orucs et al on the other hand have reported a prolapsed myoma associated with pregnancy of 18 weeks gestation in which a total abdominal hysterectomy had to be performed as during myomectomy, the proximal end of the fibroid could not be reached. ${ }^{4}$ Another case has been reported by Sengupta $S$ et al in which a woman presented at 36 weeks gestation with a prolapsed fibroid of $12 \times 14$ $\mathrm{cm}$. In her case, baby was delivered by cesarean section followed by vaginal myomectomy. ${ }^{5}$ Vaginal myomectomy is recommended as the initial treatment of choice for a prolapsed fibroid as cesarean section can be avoided in such cases as was done in our case. Myomectomy of a prolapsed cervical fibroid is technically not challenging. In our case a prolapsed cervical myoma was enucleated and baby delivered by breech extraction through vaginal route. The stalk of the fibroid could be reached in our case without difficulty. Dissection of the fibroid off the cervix was initially difficult, but after a plane was found, the fibroid could be removed much like at the time of any other myomectomy. Management of prolapsed fibroid in pregnancy can be challenging because of the increased risk of hemorrhage associated with myomectomy. Tian et al reported 17 cases of cervical leiomyoma in pregnancy in which they reported mean blood loss at delivery of $350-420 \mathrm{ml}$, mean duration of stay in hospital after delivery of $7.9+3.9$ days and three cases of severe hemorrhage or infection postoperatively necessitating hysterectomy. ${ }^{6}$ In our case, there was minimal blood loss of about 100 $\mathrm{ml}$, patient stayed in hospital for 7 days and there was no postoperative hemorrhage and infection. On follow-up, patient was asymptomatic and cervix was normal.

\section{REFERENCES}

1. Cooper NP, Okolos. Fibroid in pregnancy-common but poorly understood. Obstet Gynecol Surv 2005 Feb;60(2):132-138.

2. Erian J, El-Toukhy T, Chandakas S, et al. Rapidly enlarging cervical fibroids during pregnancy: a case report. J Obstet Gynaecol 2004;24(5):578-579.

3. Kilpatrick CC, Adler MT, Chohan L. Vaginal myomectomy in pregnancy: a report of two cases. South Med J 2010 Oct; 103(10):1058-1060.

4. Oruç S, Karaer O, Kurtul O. Coexistence of a prolapsed, pedunculated cervical myoma and pregnancy complications: a case report. J Reprod Med 2004;49(7):575-577.

5. Sengupta S, Reddy K, Pillai M. Prolapsed cervical fibroid in pregnancy: a challenging obstetric dilemma. J Obstet Gynaecol 2006 Nov;26(8):823-824.

6. Tian J, Hu W. Cervical leiomyomas in pregnancy: report of 17 cases. Aust N Z J Obstet Gynaecol 2012 Jun;52(3):258-261. 